\title{
Public Health Law Perspectives: Nutritional Supplements and Doping In Sports
}

\author{
Elena Atienza-Macías
}

PhD in Sports Law by the University of Deusto.

Basque Government Postdoctoral Researcher, University of the Basque Country, University of Coimbra

Chair in Law and the Human Genome R.G., Centre for Biomedical Law, Bilbao, Spain-Coimbra, Portugal

Correspondence: E-mail: elena.atienza@ehu.eus

Received: April 9, 2018

doi:10.11114/ijlpa.v1i1.3242

\author{
Accepted: April 22, 2018 \\ Online Published: April 25, 2018 \\ URL: https://doi.org/10.11114/ijlpa.v1i1.3242
}

\begin{abstract}
In this paper the author intends to set forth, briefly but rigorously, the mix of legal issues around the extended use of (incorrectly) so-called "food supplements", trying to express in full the complex inventory of problems arising from the lack of ad hoc regulation in the field of doping in sport.
\end{abstract}

Keywords: Doping in sports / Legal perspective / Nutritional supplements / Public Health / Health Legislation.

\section{State of the Art}

In the field of doping suppression, there is a tenuous dividing line between food supplements and drugs. In this regard, it is especially alarming that such supplements may contain substances that are potentially toxic to athletes, components that are prohibited under anti-doping regulations either by themselves, as prohormones or as metabolic products.

In fact, a large percentage of positive results in doping controls are due to the presence in, or contamination of supplements with substances listed in the well-known "Prohibited Substances and Methods List".

On the other hand, we should point out that it is not only high-level athletes who use this type of substance to compete more effectively: their use is widespread in certain social activities, such growing muscles or losing weight. In these cases, we often find people who do not practice a sport purely for "leisure" but rather, to achieve certain ideals of beauty through the design of their body shapes, such as bodybuilding - practices specifically aimed at the cultivation of the body, in gyms, fitness rooms and the like. Not only are these substances being used more widely, they are easy to obtain and there may be a lack of security and quality control.

\section{The Importance of Doping: Its Impact on Health}

\subsection{The Topical Nature of the Subject}

The concern of legislators for regulating doping in sport is not a trivial matter, but a reflection of a concern that has arisen within society - since law always trails behind society, Ubi jus, ibi societas-and more specifically in the sporting world. All of this has its raison d'être in the irrefutable fact that the phenomenon of sport has acquired enormous importance in recent decades, projected into all areas of life.

It is significant that, of the many fields that demand interdisciplinarity and are extremely topical, the most paradigmatic example is, of course, sport; and in particular, the risks that increasingly threaten it. Among these dangers, doping is key - both because of the serious threat it poses to individual and public health, not only for high-level athletes but amateurs as well, and for its undermining of the principle of competition in sport, whose most notorious cases have had an outstanding impact on public opinion. Certainly, in recent years this problem has acquired a ever-greater role in view of such famous cases as that of Lance Armstrong - the most recent high-profile case of positive doping in world sport - and within Spain, the controversial case of cyclist Alberto Contador, the archetype, as we shall see, of the "contaminated nutritional supplement theory".

However, when we look into doping we find extremely delicate considerations together with very serious and complex problems in a resolutely multidisciplinary area which is therefore imbued with all manner of ramifications: economic, political and media, to mention the most obvious, but also, as we discuss in this chapter, the areas of law and 
health - sport being the space in which the relationships of the "food-sport-health axis" show the greatest intensity and conflict.

\subsection{An Overview of the National and International Regulatory Scene}

In recent years, we have been perplexed to witness incessant changes in the regulation of doping in sport; changes in the rules of the game that have meant, not only that sporting law has already won, at this point, its own autonomy and identity as a legal discipline but that the doping phenomenon is the playing field for a comprehensive, differentiated, independent legal analysis.

In particular, 2015 was an especially fruitful year for the study of the legal issues triggered by doping, given the recent entry into force, on 1 January, of the third version of the World Anti-Doping Code (CMA) — a project that began within the World Anti-Doping Agency (WADA) at the end of 2011 with an intensive process of consultations with the stakeholders involved in the fight against this scourge in sport, compliance with which will ensure progress essential to eradicate doping.

At the same time Spain has embarked on the relevant process of adapting their legislation to this new code worldwide, introducing a legislative model relatively recent in appearance. In this sense, in 2013 Spain rushing the relevant task of development and approval of the Fundamental Law 3/2013, 20 June, protecting athletes' health and fighting against doping in sports (FL 3/2013) — which abrogated its predecessor, the fundamental law of 2006. A particularly relevant fact, due to the unique legal framework which it promises, with comprehensive protection of athletes' health above and beyond the problem of doping. This new law places special emphasis on the importance of establishing a complete system of health protection that will benefit, from all points of view, the main subjects of this law, namely people who carry out any sporting activity. According to this argument, this law far exceeds what would be a simple anti-doping standard.

In this regard, the intention of the national legislator has been to include a powerful system of health protection for people performing any sporting activity. In general the new law seeks to differentiate measures that affect athletes in general, which are positive measures to prevent risks to health associated with sports, and specific measures, more limited in scope, in the fight against doping.

Indeed, this legal line-up goes further; doping is not its main element, and without prejudicing the unquestionable importance of doping regulation, the new law tries to configure it, in fact, as one element in a system to protect athletes' health, for which the proposed reform has been a step forward.

A special consideration is that athletes' health is the backbone of the law and doping is revealed as the "pathological part" of that system, as a "scourge" that we must try to eradicate, because it affects the protection of athletes' health, fair play in sport, equality in competitions, and sport's ethical dimension (the pillars of the anti-doping regime). Also for this reason, the prevention and control of doping can be considered as an element in a much broader reality, namely protection of athletes' health.

Among the organizational innovations set out in the rules of 2013, the new Spanish Agency for Health Protection in Sports (AEPSAD) — which replaces the flagship State Anti-Doping Agency (AEA) —is now configured as an independent public body responsible for the protection of athletes' health, with competences in the field of prevention, suppression and investigation. Also new and interesting here is that the 'Doping Control Laboratory' becomes independent from the Agency, does not form part of its governing bodies, and is managed autonomously; to which we will pay attention in later pages.

\section{Nutritional Supplements as Doping Substances?}

\subsection{Stating the Problem}

Nutritional supplements (also known as "dietary supplements" or "food supplements") are defined legally-by the Royal Decree 1487/2009, of 26 September, on food supplements — as food products consisting of concentrated sources of nutrients and presented with the aim of complementing the intake of such nutrients in the normal diet. In the light of this Royal Decree, there is a wide range of nutrients and other elements that may be present in food supplements including, among others, vitamins, minerals, amino acids, essential fatty acids, fibre, various plants and herbal extracts.

There is no doubt that an athlete must take a special caution when consuming supplements, evaluating the need for their consumption with the help of a nutrition professional. If they are deemed necessary, they should avoid buying products labelled in foreign languages, purchased through third parties or over the internet without knowing their origin and level of confidence.

An issue that links with this is the fact that the vast majority of substances banned in sport are found in drugs coming to 
the athlete from clandestine markets. The "Council of Europe Convention on the counterfeiting of medical products and similar crimes involving threats to public health" (MEDICRIME Convention) applies. In this regard, the Council of Europe created in December 2010 the so-called MEDICRIME Convention which constitutes, for the first time, an international treaty in the field of criminal law on counterfeiting of medical products that pose a threat to public health. Spain is the second country that has ratified the Convention. MEDICRIME gives States a powerful tool to combat this scourge: the introduction of common minimum standards on criminal law and litigation among all subscribers of the Treaty countries. It also provides contact points in national health systems, reference laboratories, the police and the Customs authorities to ensure the exchange of information and cross-border cooperation. So the ratification of this Convention and its entry into force means an important step in the pursuit of the illegal trafficking of medical products from the international point of view, including the substances and methods prohibited in sport.

In line with the above, the former Director of the AEPSAD (Enrique Gómez Bastida), and Director of the Spanish Agency for Medicines and Health Products or AEMPS (Belen Crespo Sanchez-Eznarriaga), signed a framework collaboration agreement - the Collaboration Agreement between the AEPSAD and the Spanish Agency for Medicines and Health Products, Madrid, Spain, May 26, 2015 - whose objective is to articulate lines of cooperation, collaboration, coordination and communication between the two agencies in the protection of athletes' health through the prevention of and fight against doping in sport. In this sense the AEPSAD had detected that some violations of the anti-doping regulations were derived from, among others things, the proliferation of illegal drugs that contain substances whose consumption can pose a risk to the health of athletes, including substances banned in sport or the acquisition of drugs outside the channels legally established for their custody, preservation and dispensation.

Now, at this point we wonder whether nutritional supplements have the same control as drugs. The answer, as we might have expected, is no; if nutritional supplements were regulated as drugs they would not be in the legal limbo which they are in, and it would be irrelevant to talk about problems of control and regulation. In fact, food supplements do not count as medication and are not subject to the specific controls on the

pharmaceutical industry; so they can include in their composition, contamination with undeclared substances which are prohibited in sport. And in practice it turns out that a large percentage of positive results in doping controls are due to the presence or contamination of food supplements with substances included in the list of substances and methods prohibited in sport.

The problem is accentuated because an athlete can be sanctioned because of a positive control due to a prohibited substance in a supplement. Thus, in connection with the sanctions regime and the fight against doping, the AEPSAD warns that the detection of the presence of a prohibited substance or its metabolites or markers in an athlete's bodily specimen is classified as a very serious violation, punishable by a two-year suspension in accordance with article 22.1 of the Law 3/2013. In these cases, to claim lack of knowledge of their presence due to ignorance or a faulty label, is not a valid justification.

\subsection{International and European Legislation}

In the context of a crackdown on doping, there was a major step forward on October 19, 2005, during the 33rd General Conference of UNESCO held in Paris, when the International Convention against Doping in Sport was approved. Once ratified by signatory countries, this permitted regulatory harmonization and the effective enforcement of the World Anti-Doping Code in the territory of the signatories. This Convention already highlighted this problem and although it pointed out that the Governments enjoy a certain degree of flexibility in terms of how they put the Convention into effect, whether by legislation, regulation, administrative policies or practices. However, the signatory States (http://www.unesco.org/new/es/social-and-human-sciences/themes/anti-doping/international-convention-against-doping -in-sport/states-parties/), including Spain which ratified the Convention on October 25, 2006, are required to adopt specific measures to:

"Encourage producers and distributors of nutritional supplements to set "best practice" in the labelling, marketing and distribution of products that might contain prohibited substances".

In the European regulatory landscape, we could highlight the Regulation (EU) No. 1169 / 2011 of the European Parliament and the Council on food information to the consumer. Known as "Regulation IAC", it entered into force December 12, 2011, being applicable from December 13, 2014, with the exception of the provisions relating to nutritional information, which shall apply from 13 December 2016. The regulation requires labeling of food supplements "in a clear and comprehensible manner" to help consumers who want to make their decisions about food and diet with greater knowledge of the facts. In addition, they "must indicate the country of origin or place of provenance of a food, given that the absence of such an indication may lead to misleading consumers as to the true country or place of origin of that product." 
Within the anti-doping agency of the United States (known as USADA), a law of great significance in this field was passed: the Designer Anabolic Steroid Control Act of December 2014, which is intended to prevent steroids being marketed as food supplements or distributed under a false labelling. The adoption of this law has been an important step in the protection of athletes at all levels and consumers from companies that sell designer steroids masquerading as supplements. As part of the USADA Mission for 'clean' (of doping) athletes, the Agency works to help athletes understand the risks associated with the use of food supplements.

\subsection{The Position of the Spanish Agency for Health Protection in Sports}

The AEPSAD alerts athletes of the possible consequences, both for their health and in terms of possible sporting sanctions, of a lack of vigilance in the purchase and consumption of food supplements. Athletes must remain active in anti-doping in sport and should ensure that no prohibited substance enters their body, being held responsible when their presence is detected.

Among the mechanisms which they have devised, and are backed by the AEPSAD, the "absence of banned substances certification program" called Informed Sport is emphasized. The international scientific group LGC (which leads the program) has been working with the Agency in order to increase awareness of the risks associated with unintentional doping which can be derived from products contaminated with substances prohibited by WADA.

The AEPSAD proactively advises Spanish athletes and sports organizations on the problem of unintentional doping and refers to Informed Sport as the most effective and widely recognized way to minimize the risk. In addition to AEPSAD educational material in Spanish aimed at its stakeholders, LGC has presented its program to the leaders of the Spanish sports supplement industry, offering its advice in the area of quality assurance.

This is a program of testing and certification of food supplements created by the British company LGC, endorsed and developed in conjunction with national antidoping organizations (such as UKAD in the UK or NADA in Germany), which gives athletes access to safe purchasing of supplements.

Informed Sport evaluates the production process and certifies the absence of contamination with prohibited substances in sport via batch manufacturing, ensuring a follow-up of the product, and the assurance that the complement consumed by the athlete is part of a batch tested and certified as "free of doping". On the website created for this purpose, the athlete has at their disposal a list of manufacturers, products and lots of them with confirmation of the absence of prohibited substances that allows them to make the right choice.

\subsection{The Doping Control Laboratory}

To the extent that nutritional supplements may be contaminated with substances not listed on the label that could give a positive result in a doping control (particularly steroids), the IOC and the World Health Organization recommended extending controls to nutritional supplements. These controls are based on analyses of biological samples taken from athletes who have participated or will participate in a sporting competition.

In this context the Doping Control Laboratory becomes vital because these samples can only be analyzed in doping control laboratories accredited by WADA, which must meet a series of requirements in terms of facilities, personnel, manuals of quality and technical procedures, and security protocols. In Spain these requirements are collected in the Royal Decree 1744 / 2011, of 25 November.

This institution is attached to the AEPSAD and, as established by the relevant regulations, acts with full functional independence in order to ensure confidence in its competence and impartiality. Also, it should be pointed out that the laboratory is responsible for the following tasks:

-The implementation and execution of the analytical tests, as well as additional control of the practice of doping, in order to check for the presence of any prohibited substance or its metabolites or any of its markers, or the use of a non-regulation method. This action will have to be done in accordance with the International Standards for Laboratories approved by the WADA and the rules of procedure approved in the development of the Fundamental Law 3/2013.

-The collection of anti-doping statistics, from both national and international samples, or from other private sector entities that might undertake analytical doping-control procedures, with full respect for data protection rules.

-Any others, to be determined by the anti-doping laboratories approved by WADA.

Finally, we should ask whether there are nutritional supplements endorsed by anti-doping laboratories. From this perspective, it should be noted that the WADA Laboratory Code of Ethics states that they will not analyze commercial preparations, except at the request of an anti-doping organization as part of an investigation. In no case will the official laboratories of the WADA provide results, documentation or warnings that support a product. 


\section{The Problem of Contamination with Nutritional Supplements: the Controversial Contador Case}

A high-profile case within this problematic is that of the famous Spanish cyclist Alberto Contador. This athlete was sanctioned with a two-year suspension, including the loss of the 2010 Tour de France - in which he tested positive for Clenbuterol-and all other victories achieved until January 25, 2011,the dies a quo established for that period, considering that the positive test of the athlete for Clenbuterol was more likely to have been caused by the ingestion of a contaminated (nutritional) supplement than by a blood transfusion or by ingestion of contaminated meat (the argument put forward by the rider). The hypothesis of contaminated food supplements was considered by Court of Arbitration for Sport as the most likely cause, although we cannot ignore the fact that the court expressly admitted that it could not be certain that this was the case.

From this point of view, the Contador case is considered as archetypal as regards the rule of objective responsibility in questions of sporting disciplinary action.

On February 6, 2012 the Court of Arbitration for Sport (CAS), headquartered in Lausanne, ruled on the case of doping that surrounded the Spanish cyclist Alberto Contador. He was sentenced to pay a fine of 2,485,000 Euros to the International Cycling Union (UCI), and to be banned for two years. The cyclist tested positive in both samples A and B in a doping test carried out in September 2010, during the Tour de France. Specifically, 50 picograms of a substance banned by both the World Anti-Doping Agency (WADA) and the UCI, called clenbuterol, were found in his body. This substance is a drug that is known to improve athletic performance. While initially, the Competition Committee acquitted the cyclist on the grounds of lack of fault or negligence - being unable to declare him liable for violation of an anti-doping standard, under Article 296 of the anti-doping rules of the UCI, which requires voluntary ingestion of prohibited substances - the CAS, however, resolved the case using the so-called "nutritional supplement theory".

With this theory, the CAS is saying that, although it has not determined how the banned substance entered the athlete's body, the most likely means was via a nutritional supplement, in such a way that if the athlete fails to demonstrate that they have been completely diligent, it is enough to condemn them under a rigorous application of the principle of objective responsibility. This case is paradigmatic in that the principle in dubio pro reo, characteristic of every branch of law, falls in favour of the principle of objective responsibility, reversing the burden of proof.

In any case, we cannot talk, in purity, of a true objective responsibility, but rather of a quasi-objective responsibility, because this does not automatically impose responsibility according to the mere result, but admits the possibility of reducing or even eliminating sanctions if the accused athlete manages to prove that there has been no fault or negligence on their part, or at least that there has not been significant blame, to which end they have to demonstrate how the prohibited substance has entered their body.

Opposite the case of the cyclist Contador, we could highlight that of Australian Michael Rogers. Unlike the Spaniard, Rogers did succesfully use the argument about ingestion of contaminated meat to be absolved of his positive test for Clenbuterol, according to a statement from the International Cycling Union (UCI). The Australian had tested positive in the laboratory in Tokyo in a control carried out on October 20, 2013. He won the Cup of Japan and was provisionally suspended by the UCI. However, the world time trial champion claimed as the cause, the eating of contaminated meat in China during his participation in the Tour of Beijing. The UCI, after consultation with the WADA, concurred with the alleged cause and acquitted him.

\section{Concluding Remarks}

A large percentage of positive results in doping controls are due to the presence or contamination of nutritional supplements with substances on the Prohibited Substances and Methods List, which corresponds to the thesis of involuntary or non-premeditated doping.

Therefore, one of the main risk factors of the nutritional supplements, alongside positive doping tests by contaminated supplements, is the fact that many athletes are using them with a patent ignorance of their side effects and recommended doses.

Part of the work of the AEPSAD - as the relevant authority in Spain in the field of protection of athletes' health and anti-doping in sport-is based on combating substances whose consumption poses risks to the health of athletes and persons performing sports activities. Its work, therefore, does not only revolve around the imposition of sanctions for violation of the anti-doping rules, but has a clear preventative function.

The problem addressed includes a very large field, including both legal and illegal medicinal products and nutritional supplements that may contain active substances that are traditionally used to enhance athletic performance and which in many cases are prohibited in sport. Therefore, the Agency inevitably includes within its duties the promotion of national and international cooperation and the exchange of information between all stakeholders, whether public bodies (health authorities, customs, security forces...) or private organizations belonging to this area. 
The AEPSAD proactively advises Spanish athletes and sporting organizations on the problem of inadvertent doping. For this purpose it relies on companies' 'quality seals' which certify food supplements endorsed and developed along with National Anti-Doping Organizations, allowing the athlete to safely purchase supplements.

All this is in accordance with the postulates of the WADA, for whom the education of athletes and their environment is a key pillar in the fight against doping, in line with the World Anti-Doping Code of 2015, which emphasizes the need to implement educational programs based on prevention, so that athletes and support staff can acquire specific knowledge of the risks related to the use of nutritional supplements.

\section{Acknowledgements}

This research is framed within the Basque Government Postdoctoral Program. Dr. Elena ATIENZA MACíAS is part of this research program which is jointly developed between the University of the Basque Country UPV/EHU (Chair in Law and the Human Genome Research Group) under the supervision of Prof. Dr. Carlos María Romeo CASABONA and the University of Coimbra (Centre for Biomedical Law) under the supervision of Prof. Dr. André Gonçalo DiAS Pereira and Prof. Dr. Alexandre Libório Dias Pereira. Likewise, the author would like to acknowledge the grant received from the Basque Government (Ref. No. IT1066-16) to support the activities of the Basque University System Research Groups.

\section{References}

Amorós Martínez, A. (2012). El caso Contador: una lectura reposada a la luz del borrador del CSD sobre el proyecto de ley orgánica de lucha contra el dopaje, Revista Aranzadi de Derecho de Deporte y Entretenimiento, 36, Aranzadi, Pamplona, Spain.

Atienza Macías, E. (2015). 2015 WADA code comes into effect: significant changes in the Spanish legal arena, The International Sports Law Journal (ISLJ), Asser Press — Springer, Berlin-Heidelberg, Germany, 15(1), 49-54.

Atienza Macías, E. (2014). Doping and health protection: a review of the current situation in the Spanish legislation, The International Sports Law Journal (ISLJ), Asser Press — Springer, Berlin-Heidelberg, Germany, 14(1-2), $138-142$.

Auneau, G. (2001). Dopage et mouvement sportif, Presses universitaires du sport, Voiron, France.

Dumas, P. (1977). Le doping, Gazette Médicale de France, París, France.

European Court of Human Rights. (2013). Legal opinion regarding the draft 3.0 revision of the World Anti-doping Code, authored by Jean-Paul CosTA, Strasbourg, France, June 25.

Foster, K. (2003). Is There a Global Sports Law?, Entertainment Law, London, United Kingdom, 2(1).

Gleaves, J. \& Christiansen, A.V. (2014). The Curious Cases of Clenbuterol, International Network of Humanistic Doping Research Newsletter, Editorial, June 2014, INHDR, Aarhus University — Department of Public Health, Aarhus, Denmark.

Jones, K. (2014). Lunch and learn: WADA Code 2015 - the key changes, The International Sports Law Journal (ISLJ), ASSER International Sports Law Centre ASSER PRESS - Editorial Springer, Berlin-Heidelberg, Germany, 14(1-2), 143-147.

Kornbeck, J. (2008). Anti-Doping in and beyond the European Commission's White Paper on Sport, The International Sports Law Journal, Springer, Germany, 3(4).

McNamee, M. \& Tarasti, L. (2010). Juridical and ethical peculiarities in doping policy, Journal of Medical Ethics, 36(3). https://doi.org/10.1136/jme.2009.030023

O’Leary, J (2001). Drugs and doping in sport. Socio-legal perspectives, Cavendish Publishing, London, United Kingdom.

Patel, S. (2015). Exploring Key Themes. Safety: the precautionary principle, Inclusion and Exclusion in Competitive Sport. Socio-Legal and Regulatory Perspectives, Routledge, New York, 155-172.

Pérez Triviño, J.L (2013). The Challenges of Modern Sport to Ethics From Doping to Cyborgs, Lexington Books, New York, United States of America.

Prokop, C. (2000). Die Grenzen der Dopingverbote, Nomos Verlagsgesellschaft, Baden-Baden, Germany.

Schönfelder, M. (2007). Nutritional Supplements - Creatine, Biomedical Side Effects of Doping, Institute of Public Health Research, Technische Universität München, Munich, Germany, 154-170.

World Antidoping Agency. (2014). Sochi 2014. WADA's Olympic and Paralympic Preview, Play True, Montreal, 
Canada.

World Antidoping Agency. (2013). The World's Anti-Doping Code. Collaborative. Coordinated. Complete, Play True, No. Montreal, Canada.

World Antidoping Agency. (2013). WADA Symposium on Gene and Cell Doping, Play True, Montreal, Canada.

World Antidoping Agency. (2012). The Code in Review. Moving ahead through stakeholder consultation and the Code Review Process, Play True, Montreal, Canada.

VV.AA. (2013). Derecho deportivo. Legislación, comentarios y jurisprudencia, Tirant lo Blanch, Valencia, Spain.

VV.AA. (2011). Doping and Anti-Doping Policy in Sport: Ethical, Legal and Social Perspectives, Routledge, London, United Kingdom, 2011.

\section{Copyrights}

Copyright for this article is retained by the author(s), with first publication rights granted to the journal.

This is an open-access article distributed under the terms and conditions of the Creative Commons Attribution License which permits unrestricted use, distribution, and reproduction in any medium, provided the original work is properly cited. 